\title{
The information processing predicament of non-English-speaking students in an academic community of practice
}

\author{
Charles Adedayo Adebanji \\ Midrand Graduate Institute, Gauteng, South Africa. Foundation and academic support Programmes unit
}

\begin{abstract}
This study set out to explore the information processing dilemma of French-speaking students (FSS) in an academic community of practice (ACOP). Utilising a single case study approach, semistructured interviews, focus group interviews, narrative inquiry, situated learning theories and transformative learning theory, French-speaking students interpreted academic information from English to French and back to English before they could construct scholastic knowledge. The paper suggests that facilitators of learning should ensure adequate interaction between them and the other stakeholders. They are also to ensure the use of technology to enhance the processing and transformation of academic information by the French-speaking students.
\end{abstract}

\section{Introduction}

It is no longer a matter of controversy that foreign students travel out of their comfort zones in search of international degrees all over the world (Kim, 2011, p.281). Students pursue international study for a number of reasons. These include the opportunity to navigate a dissimilar culture, cultivate new ways of reasoning and acting, meet new friends and enhance their cross-cultural knowledge and expertise (Andrade, 2006). According to Sherry, Thomas and Chui (2010, p. 33), foreign students "may develop new outlooks, increase their selfesteem and confidence, and mature as a result of their independent life experiences in another culture." Previous studies reveal that they could experience different challenges due to language and cultural shock, academic and relational problems, ethnic discrimination, inadequate social support, alienation and homesickness (Yeh \& Inose, 2003). Andrade (2006) posits that the acquisition of English language skills is vital for the academic adjustment of international students. What this implies is that it is important for processing academic information. In the South African terrain, international students are found in both public and private tertiary institutionsdespite the attendant challenges they negotiate. There is an on-going research about how students adapt to novel scholastic and cultural mores all over the world (e.g. Andrade, 2006; Sherry, Thomas \& Chui, 2010; Xue, 2013). However little research is being done at the private tertiary institutions of South Africa on how they process academic information.

Based on the reality that the FSS explored in this paper were non-English-speaking students in a dissimilar environment, it was hypothesized that certain vital dynamics likely transpired as they intermingled with lecturers and the other students. To unravel the intellectual puzzle raised in this paper, I sought to answer the following research question: How do French-speaking students engage in processing scholastic information in the academic community of practice (ACOP)? The discussion is set out as follows: First, I present the research context and a review of the literature. Second, the chosen theories of action are discussed. Third, the research strategy employed in the study is discussed. Fourth, the findings from the study are juxtaposed with the theories of action and the moorings in the voluminous literature to herald the phenomena under investigation. Fifth, conclusions are drawn in an attempt to make recommendations fit for practice.

\section{Research context}

The study was undertaken at the main campus of a private provider of higher education in South Africa, pseudonamed Einstein College (EC). EC was established in 1989 and hires 130 permanent and contracted academic staff members. The institution also employs 81 support and organizational employees (Steyn, 2011). The institution has seen tremendous growth in the last three years. Less than 5\% of the student population was from French-speaking countries as at February 2013. The following information (Table 1.1) provides evidence that the institution has tremendously grown and details the staff strength as at March 2013 when I conducted documentary analysis. The information was compiled from 2006 to 2013. 
The information processing predicament of non-English-speaking students in an academic.....

Table 1.1: Staff population, facilities available and student population at Einstein College

\begin{tabular}{|l|l|}
\hline \multicolumn{1}{|c|}{ MARCH 2006 } & \multicolumn{1}{|c|}{ MARCH 2013 } \\
\hline 986 students & 4300 students (based on registrations to $13^{\text {th }}$ February 2013) \\
\hline 87 staff & 376 staff \\
\hline 8 student advisors & 96 student advisors \\
\hline 19 lecture venues & 54 lecture venues \\
\hline 6 computer labs & 22 computer labs (including libraries \& internet Cafes) \\
\hline 1 main campus & 1 main campus plus 11 satellite campuses \\
\hline 350 capacity student residence & 1024 capacity student residence \\
\hline
\end{tabular}

A total of 17 accredited degrees were offered across six faculties, which were mainly served by the predegree programme. The pre-degree programme is a separate faculty on its own, which makes the total number of faculties at EC equal to seven. EC is vested with degree-conferring authority by the Council on Higher Education (CHE). Consequently all qualifications are accredited by the CHE. I was a staff member at the main campus of EC.

The FSS had their local languages but did not use them on campus. They mainly spoke with other FSS in French when not in class. At the campus FSS were in the midst of South African students (SAS), other international students and lecturers. The South African languages spoken on campus were Zulu, Sotho, Sepedi, to mention but a few. These South African languages were audibly spoken in the class bySAS during group work sessions. Other international students from countries like Ghana, Nigeria, Lesotho and Rwanda spoke English because it was the language of instruction and interaction in the communities of practice (COP). However, when international students from the same country met, they retracted to their enclaves and spoke their indigenous languages, but not to the point that they were heard by the majority of students at EC. The majority of SAS at EC generally spoke Zulu because it was the universal language they could come to terms with. Black South African lecturers also spoke Zulu, Sepedi and Sotho but not openly because according to the policy at EC, English was the academic language. White South African lecturers also spoke Afrikaans but it was not officially recommended. Lecturers were drawn from a wide range of African countries in an attempt to internationalize EC. However, there were more South African lecturers than foreign lecturers but the ratio balanced out to cater for the academic setting in terms of student population and diversity.

\section{Theoretical groundwork}

According to Angelo's (1993) model article, an exploration of students' learning styles assistsfacilitators of learning to recognise how their students study more successfully.It follows that when lecturers understand how students process academic information, they would know how to facilitate learning. According to Tinto (1975, p.103), there is an indication that communication within the academic institution may be taken as a valuable predictor of academic performance or failure among university students. It is presumed that this can only occur if the communication between novices and experts in the ACOP is unscathed. Inadequate incorporation among the FSSwill be taken to imply an inability to take responsibility for learning English. Taking responsibility to learn English would imply that they are ready to explore ways of interacting with peers in possession of the required vocabulary for scholastic activities. Group work is a proven avenue that enhances the linguistic adeptness of international students (Xue, 2013). Research has shown that foreign students' outlooks towards group work goes via changes from initial reluctance to adapt or abhorrence to later adjustment or tolerance. The duration for their linguistic adaptation could span from six months to a year (Xue, 2013).It implies that it could take foreign students up to a year before they are able to adequately process academic information to the point that yields results.

Custers and Boshuizen (1997) contend that learning is crucially a latent process because only those engaged in learning can take the initiative to learn and reflect on what they decide to learn. It may thus imply that at the interphase, transformation of acquired information ensues before meaning making is achieved. SinceFSS have changed from their usual environment to an unusual one, it is considered that an exploration of how they negotiate this transition is important. My philosophy is based on my findings in the literature that alterations do occur in terms of how students learn, what they esteem as vital to learn and the milieu in which the learning occurs (Slotnick, 2001; Lloyd, 2007) because of identity shifts.It is thus important to explore the learning trajectory of FSS because it gives an indication of how they construct knowledge. It also provides the opportunity to suggest ways of improving how they learn if the trajectory involves a tremendous expenditure of intellectual resources. Othman Talib et al. (2009) posit that facilitators of learning should ascertain thelearning preferences and styles of their students. An understanding of how rapidly the students learn could then be harmonised with instructional methodologies that are considered fit for learning to ensue. Othman Talib et al. (2009) ascertain that an understanding of students' learning styles will equip them with the understanding about their strengths and weaknesses about learning and also make them more optimistic about learning.If students are incapable of efficiently processing academic information, how would they be optimistic about learning? 
I conceptualize information processing as an intrinsic technique, used by students to decipher how they learn. In an attempt to foreground my hypothesis on the notion that information processing can be regarded as learning style, I subsequently herald the definitions and arguments put forth by different scholars in the voluminous literature.Chai et al. (2013) define learning style as dissimilar tactics of learning. They contend that an approach that gives an indication of how students learn is to explore their learning styles. It occurs to me that Chai et al. (2013) are indirectly saying that the capacity of students to interpret, transform and apply academic information in context is dependent on how they utilize the information to their advantage until learning evolves. It is thus speculated that the necessary transformation occurs within the cognitive realm as students engage with learning. This undoubtedly impacts on their academic achievement profile. My statement is echoed by Dunn and Griggs (2003) who argue that the academic achievement profile of students is associated with how they learn. The definition of learning styles is not limited by boundaries (Chai et al., 2013). Chai et al's. (2013) intellectual argument that the definition of learning styles is boundless is supported by the scholarship of Boyle, Duffy, and Dunleavy (2003) who argue that the process of learning is not simple. They argue that the study of learning styles remains a gap to fill and that the exploration of effective learning initiatives is needed to explore the relationships between diverse perspectives of learning. Stewart and Felicetti (1993) describe learning styles as those learning prospects that inspire a student to learn. It implies that if the FSS would negotiate the information processing trajectory, they would have to place the prospects motivating them at the vanguard of every predicament they negotiate. Fleming (2001) expresses learning styles as "an individual's preferred ways of gathering, organizing, and thinking about information (p. 1). Consequently how information is gathered, organised and transformed become an intellectual puzzle in this study. Vermunt (1996) intellectualises learning styles not just as universal (typical) or chosen processing approaches, but as regular configurations of learning activities that are methodically associated with learning philosophies and motivational alignments. Consequently I take the effrontery to problematize how FSS logically structure their learning experiences, learning philosophies and how they are motivated to align these concepts for learning to take place. I take a look at the suggestions of Acharaya (2002) that the theories of learning can be explored and consolidated in four different perspectives namely (a) The student's personality (b) Information processing (c) Social and circumstantial interaction and (d) Adopted methods of instruction. Consequently these four perspectives of learning are considered to explore the information processing predicaments of FSS at EC. These claims in the literature require theoretical scaffolding. Therefore the following theories of action become applicable.

\section{Theories of action}

In the COP framework new entrants are referred to as novice learners in the midst of experts such as lecturers, deans, student advisors and different academic managers. Based on the COP framework both novice and experts are stakeholders, drawing on Otten (2009) and Wenger (1998). Indigenous and other international students are stakeholders in their own rights with dissimilar cultural and academic potentials as well as diverse information processing capabilities. Since the tenet of operation in COP entails interacting with one another, other stakeholders' information processing abilities should reach an alignment with how the foreign students process information for effective interaction to take place. This state of alignment is presumed to be attained when all stakeholders are proficient in English. The interaction between the FSSand the other stakeholders constitutes the basis on which the information processing predicaments of FSSis explored. The interactionsamong stakeholders are thus weighed under the tenets of specified curriculum of study in the different COP at EC.Since the learning encounters of FSS took place within an academic domain of influence, it becomes vital to usesituated learning theory to comprehend how they learn. My use of the situated learning theory by Lave and Wenger (1991) in consonance with the information processing theory is important because situated learning theorists "place knowledge and understanding at the intersection of the individual and the environment" (Durning \& Artino, 2011, p. 191).Situated learning theory highlights the importance of the participants, the setting, and their communications. Consequently the information processing predicaments of FSScan be explored within the limits of interaction among members in the COP. The learning facilitation by lecturers alone becomes insufficient, although very important, drawing on Durning and Artino (2011, p. 196). During learning facilitation exercises and group work activities, the ease at which meaning is made becomes crucial. A key area of importance is the interaction of FSS with English proficient peers during group work activities. Therefore the legitimate peripheral participation (LPP) theory by Lave and Wenger (1991) becomes useful to analyse their learning trajectory as they process academic information. According to the interpretation of cognitive apprenticeship, the FSS are referred to as cognitive apprentices, drawing on Durning and Artino (2011). They are cognitive apprentices because they learn how to structure and articulate academic information for learning to evolve. It means that their presence in a new academic domain involves devising how to manage academic information to suit their prior learning techniques until they become experts in the COP. It is thus pivotal to know that "cognitive apprenticeships, communities of practice, and legitimate peripheral participation 
epitomize the situated nature of knowledge, thinking, and learning in everyday practice" (Durning \& Artino, 2011, p. 191).

It is also significant to know how transformative learning occurs. Transformative learning among adult learners has been explored in the literature (e.g. Cranton, 1996; Mezirow, 1997). Transformative learning, as described by Mezirow (1997) is "the process of effecting change in a frame of reference" (p.5). As it applies to this study, the FSS would be seen as engaging in transformative learning if they choose to effect changes in received and discovered information as they interact with frames of reference. Prior to studying in English, they already cultivated a sequential body of experience in their interaction with people in their usual language of communication. How their information gathering experience undergoes metamorphosis, leading into learning becomes important. If this occurs they would be regarded as having undergone transformative learning, a scenario which reveals that they have devised their own ways of overcoming linguistic barriers capable of impeding learning. According to Mezirow (1997), adult learners have developed a logical body of experience in their dealings with people, principles, state of mind and accustomed responses which are frames of reference. Frames of reference are the scaffolds of suppositions that enable us to comprehend our experiences with the environment. They carefully inform and set boundaries for expectations, insights, reasoning and frame of mind. Furthermore they inform the next step to take in processing information. The moment this is achieved, actors spontaneously navigate from one mental mode to the other, depending on what they engage with. Consequently actors are at liberty to discard thoughts that do not align with their prejudices, classifying such notions as unfit for consideration. When conditions are right, those who engage in transformative learning advance toward a frame of reference that seems more comprehensive, discerning, thoughtful, and sums up what they have experienced (Mezirow, 1997).

In this study, the relevant frames of reference confronting the FSS would be the other stakeholders in the COP. A frame of reference comprises reasoning, volition (the desire to perform an action), and expressive mechanisms. It constitutes two dimensions: the mind's usual way of processing information and perspective. Conducts of the mind are wide-ranging, nonrepresentational, positioning, usual ways of reasoning, sensation, and performance directed by suppositions that establish an array of challenges. These challenges may be racial, group, didactic, monetary, administrative, or mental. The mind's usual way of processing information is expressed in a definite perspective - the pattern of belief, value perception, a settled way of thinking, and sensation that informs a definite interpretation (Mezirow, 1997). Therefore it seems as if learning style, information processing and transformative learning are within the same domain of analysing information that leads to cognition and meaning making.At EC, the mode of learning facilitation involved the initiation of information from the lecturers via technology enhanced learning, combined with group work activities, to consolidate learning. This route of learning facilitation predisposes this study to using the abovementioned theories to explore how the FSS engaged in processing information. My postulation is meaningful because the learner cannot be isolated from the learning context, as suggested by Lave (1988).

\section{Research strategy}

The research strategy utilised in this study was qualitative. I embraced the narrative inquiry and case study of EC. The data gathering procedure entailed in-depth semistructured and focus group interviews.Lecture room observations over a period of one and a half years before the study commenced was done. A careful observation of the research site and respondents was conducted to capture the environment of EC. My presence at EC a year and a half before conducting the study enabled me to make decisions in terms of the research respondents and to engage with EC to earn the trust of my research respondents. As noted by Creswell (2007, p.37) I gathered data in the site where respondents negotiated the issue or problem under investigation. The study sample was drawn from EC in the Johannesburg area of South Africa. Since the research was to explore the information processing predicament of French-speaking students in an ACOP, 28 French-speaking students were purposively drawn from the pre-degree programme to the third-year degree programme. These comprised citizens of Cameroon, Gabon, the Democratic Republic of the Congo (DRC), Chad Republic and Benin Republic in West Africa. Separate semistructured interviews were conducted with 5 lecturers who taught them, one of the deans and an academic manager.

Additional data were collected in the first semester of 2013 at the research site via 2 focus group interviews with another cohort of French-speaking students from the pre-degree to the third-year degree programmes. Separate focus group interviews comprising 19 FSS were conducted out of the previously interviewed French-speaking students that were interviewed one-on-one in 2012. In 2013, 1 (one) Frenchspeaking student was interviewed to complement the semistructured interviews conducted in 2012. This action was embarked upon to support the previously collected data in 2012 , in an attempt to increase the depth of investigating this single case thus and enhance the trustworthiness of the study. A second round of semistructured interviews was conducted with the previously interviewed FSS on areas that were not covered in 2012. Each interview lasted between 30 minutes to an hour. The interviews were video-recorded and transcribed 
to ensure analysis of obtained data. The data were analysed using thematic analysis technique as suggested by Braun and Clarke (2006). Bogdan and Taylor (1975) propose that an investigator normally gains access to an establishment in an attempt to conduct research by seeking permission from relevant authorities such as the management. Therefore permission was sought and granted by the Research Committee of EC to conduct this study. Out of all the FSS interviewed, only six were my students and at the time of the first round of interviews in 2012, they had already completed the mathematics module that I taught them. This paper forms part of the findings from my doctoral study.

\section{Findings}

The suggestions of Acharaya (2002) that the theories of learning can be explored and consolidated in four different perspectives namely (a) The student's personality (b) Information processing capacity (c) Social and circumstantial interaction among students and (d) Adopted methods of instruction, formed the basis of my interviews, analysis and the interpretation of data. Pseudo names are assigned to the interviewees. The narratives used to support claims are taken from the semistructured and focus group interviews conducted with them. Diminished proficiency in English was a major challenge to their ability to process and transform academic information.

\section{The information processing predicament of FSS}

I initiate this discussion by looking at Agness, a pre-degree student of EC from Gabon. She said, "English is difficult for me to understand. So, going back and starting to learn with the other students in English is a problem." A major contributory factor to Agness' information processing predicament was an inability to comprehend English. Using Acharaya's (2002) lens, Agness was shy, and incapable of intermingling with peers, especially when it was time to engage with the other students in the classroom. She was compelled to socialize in circumstantial ways because she belonged to COP which necessitated that she had to interact with her classmates during group work activities in the lecture room. In the COP framework students are required to use English to communicate. It was not unlikely that her incompetence at transforming information to comprehensible format contributed to her passive behaviour during group work activities in the lecture room. She revealed her trajectory of processing information in the following way:

Researcher: Can you tell me how you understand academic information during lectures and personal study times?

Agness: Sometimes, I do translate words from English to French, and back to English when it is too difficult to understand the words in English, I try to understand it in French. It is slowing my learning experience down a lot, but I have to do that for now until I improve. It is easier to write in English than to speak in English because I am shy in case I make mistakes.

Erika was a female FSS from Gabon, admitted to the pre-degree programme to study Biomedicine. She comes from a family of seven. She had been a student atEC for 8 months as at the time of this interview. The prominent narrative used to describe her storyline points in the direction of earnestly desiring to study in English. She had a little knowledge of English before she came to EC.She said, "I learned English in Pretoria at the English school called Prestige for 7 months." Erika expressed her views about her predicament by saying, "The most difficult thing for me is the English. I carry the English dictionary everywhere I go so as to learn new words." She had a reserved personality but was also mandated to participate in group work activities, which led her to socialising circumstantially with peers in the COP. Her information processing predicament is thus presented through the following vignette:

Researcher: How easy is it for you to process academic information during lecture and personal study time?

Erika: I would pass my examinations better, if we are taught in the medium of French because I study twice. For example in the maths class, it took me time to understand what was being said. I had to translate to French first before I could understand what the lecturer was saying. For the human development module, I also translated to French before I could understand.

Erika's response to my question had an undertone that signalled the challenge involved in learning in another language. We are also informed that people who are involved in learning through a chosen format do so by taking the initiative to learn despite challenges at their disposal. The narratives from Agness and Erika bring the philosophy of Custers and Boshuizen (1997) to limelight that learning is crucially a latent process because only those engaged in learning can take the initiative to learn and reflect on what they decide to learn. They both reflected on what they had to learn and got an indication that it was tiring and time consuming. As echoed by Erika, she reflected on her latent experience and found that she studied twice due to what I refer to as "learning by round tripping information." Sincetheywere linguistic novices in the COP as far as the use of English was concerned, they expended twice the time taken by English proficient students to learn. Translation of curriculum 
content from English to French and back to English was a tedious exercise used by FSS to process and transform academic information until cognition was reached. Their experiences show that alterations do occur in terms of how students learn, what they esteem as vital to learn and the milieu in which the learning occurs as suggested by Slotnick (2001) and Lloyd (2007).It thus implies that facilitators of learning should ascertain thelearning preferences and styles of their students, especially in a multiculturally diverse classroom. I concur with Othman Talib et al. (2009) that an understanding of how rapidly students learn could be synchronized with instructional methodologies that are considered fit for learning to ensue. In my review of the literature, a question was raised that if students are incapable of processing academic information efficiently, how would they be optimistic about learning? To my amazement, all the FSS were not discouraged about learning despite their challenge of having to spend about twice the time necessary to study. A major reason for their determination was due to their decision to be bilingual/multilingual because they had a philosophy that it would open doors of opportunities for them in the future. The experiences ofAgness and Erika show that the process of learning among non-English-speaking students is not trivial. The non-trivial nature of learning demonstrated so far shows that Boyle, Duffy, and Dunleavy (2003) were likely on course because they described the process of learning as not simple. Although Agness and Erika were not discouraged to learn despite the arduous trajectory they took to process and transform academic information, it was not easy for them to learn. There is a departure from the findings of Stewart and Felicetti (1993) that learning styles are those learning prospects that inspire a student to learn. The kind of inspiration to learn by Agness and Erika was not a comfortable one. It was a compulsive inspiration to learn, to attain an identity. I argue that among FSS, learning styles may not always be influenced by positive inspiration alone but by emergent, compulsive and futuristic mindset to attain an identity. From the evidence gathered so far, their learning styleswere not pleasantly preferred but compulsorily employed to process and transform academic information.I add to the scholarly work of Fleming (2001) who expresses learning style as "an individual's preferred ways of gathering, organizing, and thinking about information (p. 1) by reiterating that learning style is not always a pleasantly comfortable way an individual uses to gather, process, organize and reflect on information. Learning style is seen as a non-static phenomenon that is dictated by context, goals and aspirations to attain an identity.

I introduce a third participant pseudonamed Elijah. Elijah came to South Africa with his parents who relocated from the DRC to South Africa (SA). He had his secondary school education in SA from Grade 9. He wrote his matriculation examination in SA and gained admission to EC via direct entry. He was a second year student of B.Com Marketing at EC. He could speak French, Linghala and Swahili. At home he spoke French and Swahili. He had been living in SA for 6 years as at the time of this interview, which was conducted on the $6^{\text {th }}$ of March 2013. Based on his profile he qualifies to be addressed as an immigrant but was not futuristically interested in living all his life in SA.He had linguistic challenge at the outset. His statement gave an impression that he had improved in English over a period of six years in SA. He attended an English learning centre known as ABC English when he came to SA for three months. Elijah was not as shy as Agness and Erika probably because he had lived in SA for up to six years. At this time he had gained the confidence to eloquently speak in English. He was no longer reckoned as someone compelled to socially and circumstantially interact with peers at EC.

Elijah was not left out of the rigorous struggle which entailed that he had to translate curriculum content from English to French and back to English. According to him the way FSS interpreted and made sense of scholarly tasks bordered on the route to making meaning. By the time FSS completed the process of translating from English to French and back to English the meaning of what they were translating could have been lost. He was of the opinion that as long as a French-speaking student refuses to surround him/herself with English-speaking students, linguistic challenge could persist. I present his case:

I translated from English to French and back to English because of the way we think as Frenchspeaking students. I processed words from English to French. It had to do with speaking French all the time, so I reasoned in French. However if you speak in English, your thoughts would be in that line. It is important for a French speaker to change his/her environment so as to learn English. If a French speaker sticks to Frenchspeaking students all the time, such a student would never learn English.

Elijah's emphasis on the necessity for a French-speaking student to interact with English-speaking students points to the importance of operating in the world of experts in COP, where a novice gains expertise by interacting with more knowledgeable others (MKO) as suggested by Reyes (2007). As seen through Elijah's experience, he began to learn English from MKO until he could directly process academic information after about six years of interacting with stakeholders even before he began to study at EC. These narratives attest to the notion that the mind's usual way of processing information is expressed in a definite perspective- the pattern of belief, value perception, a settled way of thinking, and sensation that informs a definite interpretation, as suggested by Mezirow(1997).

Candy's experience at EC is the fourth evidence. At the point of entry to EC, Candy could not understand English too well. Although she did a little bit of English in the DRC, this did not suffice to go 
through a degree programme in SA. As I conducted a document analysis, she obtained $99 \%$ in maths while she was in the pre-degree programme. In biology she was an average student because of linguistic challenge. During the interview, I observed that her English comprehension and vocabulary had tremendously improved. This was an indication of her interaction with MKO in the ACOP, by virtue of the designed curriculum at EC. It seemed as if time assisted her to grasp the command of English language. A notable experience of Candy at EC was linguistic challenge at the point of entry. Secondly, by the time she reached the third-year programme, her linguistic competence had improved. She narrates her experience:

My English was very bad when I got to this institution, although I did English in Congo, in an American institute where they teach English. I came to South Africa but it was very difficult for me to express myself in English. In other subjects, I was trying, like in biology I was trying to get at least 50\% because I didn't know the language of instruction.

She sought assistance from one of the lecturers who began to assist her to learn English (evidence of consultation with MKO in the ACOP). The lecturer took the initiative to teach her English in order to rescue her from her state of incommunicado. It was a remedial initiative to revamp Candy from her state of frustration because she could not effectively participate in the curriculum of EC. The role of this lecturer was an indication of the role played by an expert in the ACOP, creating the opportunity to engage beginners to engender the atmosphere of learning by interaction and integration. Candy said:

Whenever I had a problem in English, I had a lecturer who helped me. I have improved a lot because while I was in pre-degree, we had a presentation. I was there, standing before everyone and I had my laptop so I was reading from my laptop because I didn't have confidence in my English. Now, I can talk without looking and reading from my laptop in the presence of everyone.

It took a turnaround time of about 4 years to reach the stage that she reached at the time of this interview. The evidence that she had tremendously improved was found when she said she could present a topic in the presence of the other students, which was not previously the case. She had gathered sufficient vocabulary that could foster boldness to reach out to the other students.

Amanda's story with information processing constitutes the fifthevidence. Amanda (female) was a third-year Information Technology (IT) student at EC. She was from Gabon in central Africa. Amanda attended an English school in Pretoria to prepare for tertiary education for eight months. She came to study in SA because of the opportunity to learn in English. During the interview session she had this to say about her mission in South Africa:

The first advantage is the language because in my country we speak French, so I wanted to study in an English-speaking country. Secondly, the school fee is not as expensive as it is in other countries of the world. I want to learn in English because speaking in English opens more doors than speaking in French. If I am bilingual, I can find myself anywhere being at ease with other people who speak English.

Her experience was different compared to the other FSS aforementioned. She expressed her information processing acumen in the following vignette:

Researcher: How do you learn in English at this institution since you did not initially learn in English? Do you translate from English to French before you learn?

Amanda: First of all, I think it is a waste of time and it doesn't really help. If I have to translate every single word that I read to French, it means I still have to translate from French to English again in my understanding. I don't really learn like that. If it is a word that I don't understand, I take the contextual meaning by looking at the dictionary but I won't translate the whole text.

Amanda's method of processing information appears to validateAcharaya's (2002) scholarship. From her narrative she deliberately chose not to process academic information as her French-speaking peers did. Amanda's disparate learning style seems to validate Chai et al's (2013) definition of learning style. They define learning style as the different strategies of learning employed by people. I therefore suggest that the capacity of FSS to interpret and transform academic information in context is dependent on how they utilize the information to their advantage until learning evolves. Amanda took a new turn by devising how to use the dictionary to suit her information processing experience by not translating the entire learning content to French. Amanda's information processing expertise also seems to agree with Custers and Boshuizen (1997) that learning is crucially a latent process because only those engaged in learning can take the initiative to learn and reflect on what they decide to learn.

Andre was a third year biomedicine student. He was proficient in English. Andre had negotiated the transition from French to English in his six-year stay in SA. He went to study English when he newly arrived inSA for 10 months and earnestly studied English to the extent that it was difficult to recognise him as an original French speaker. Consequently I commended his English-speaking ability as I questioned him on how he succeeded in negotiating a brisk transition from French to English. He responded as follows:

Thank you for that acknowledgment that my English is quite good. Yes I went to an English school for 10 months to learn English. I couldn't even greet when I got here six years ago. I actually worked on it. When I 
got here, I had to study in English. I am a dedicated person. When I am doing something, it is either I do it or I don't. When I do what I am supposed to do, I do it the way it is supposed to be done. That is the best I could do to speak the English I am speaking now.

Two points, made by Andre brought the relevance of Acharaya's (2002) scholarship to my attention. First, Andre said, "I am a dedicated person." Second he affirmed, "When I do what I am supposed to do, I do it the way it is supposed to be done." His philosophy pointed to the issue of personality, mentioned by Acharaya (2002) as one of the ways to explore learning theories among people. Furthermore, taking the initiative to pursue challenges is implicated as an ingredient for taking responsibility for devising own ways of processing information. It implies that information processing is a function of charisma, dedication and astuteness at targetting what should be learned by students. Andre furthermore stressed his trajectory of processing academic information in this monograph:

Researcher: Have you ever translated academic content from English to French and back to English before you could understand what you needed to understand?

Andre: I have never done that but there is a saying that you hear in your own language. When someone is speaking to you, no matter the language that person is speaking to you, you will hear in your own language. Even if I am reading a book in English, my understanding would be in French because that is my native language but I would not take time to translate.

From Andre's narrative it can be implied that he advocated for briskness in terms of information processing and transformation. His experience suggests that it is possible to read in English and understand in French without having to take time to translate information. This occurs to me that FSS could be efficient at instantaneously processing information as they read in an unusual language. I suggest that at times information processing among FSS may depend on the swiftness, inevitability and briskness at which they are able to utilise acquired vocabulary in an unusual language to comprehend curriculum content.Consequently Andre's linguistic experience pointed to the requirement that FSS had to negotiate a transition from French to English before they were capable of interacting with the curriculum of instruction and its stakeholders.

In an attempt to consolidate an understanding of the information processing pathway of FSS, the following was obtained in a focus group interview session with another cohort. Out of the six FSS in this focus group interview (FGI) session, five engaged in the rigorous exercise of translating curriculum content from English to French and back to English in an attempt to understand curriculum content. They agreed that at times they did it unconsciously, out of desperation to learn. Their cases are presented:

Researcher: Do you all learn by translating from English to French and back to English?

Anthonia: The way we write words in French is totally different from the way we write in English. This is why it seems as if when we are speaking in English, we speak in the opposite direction, so as we translate from English to French, the meaning is lost.

Caira: It is something that you don't plan to do. I translate from English to French before I can understand in English.

Princess: My frequent association with French-speaking students does not help me because I still translate from English to French and back to English.

Frida: You know I am new. If I don't translate from English to French, it would be difficult for me to survive here.

Pertunia: I translate From English to French so that it can help me to understand. I think in French during the lecture period. I translate what the lecturer is saying into French in my head.

From the abovementioned narratives, it occurs to me that information processing is about mindset and cognitive reflection. Some of them saw the phenomenon of "thinking in French" as a way out of the workload of learning English via interaction with MKO.Others said it was an involuntary engagement of information with the mind, which I refer to as involuntary cognitive engagement. Using one of the tenets of situated learning, encompassed by situativity theory, it becomes clear to argue that:

“...... knowledge and thinking (cognition; i.e., situated cognition), as well as learning (i.e., situated learning), are situated in experience. Experience includes the participants (i.e., students, teachers, and patients), the culture, and the physical environment where thinking and learning occur" (Durning \& Artino, 2011, p.188).

The experiences of FSS with respect to how they engaged with information reveal to us that received information requires prompt thinking. It also elucidates the notion that prompt thinking requires brisk action, depending on environmental association with MKO who can act as experts by challenging the capacities of novices to learn by watching and doing what is required to facilitate learning.

I present a unique dimension of learning style exhibited by a cohort of FSS interviewed in a second round of FGI. Their methods of processing information pointed to the fact that auditory dissemination of information during learning facilitation by lecturers is insufficient to trigger the process of learning. A prominent challenge to their information processing capacity was the issue of pronunciation of words by 
lecturers. The issue of accents seems to be an active determinant of information processing. It implies that when lecturers pronounce words incorrectly, the meaning making acumen of students could be hampered. The translation of curriculum content from English to French and back to English could be truncated when the wrong words are used to process information. In the process the essence of the real meaning of the translated words could be lost. The following vignette expounds my interpretation of their unique way of processing information:

Onthatile: I benefit most from lectures when the lecturer writes on the board because the way we understand in French is different from the way the lecturer explains.

Stephanus: I agree with the fact that the way to understand what has been said is for the lecturer to write a summary of his presentation.

October: My time to learn comes when the lecturer writes on the board because of how I understand as a French speaker. At times the pronunciations of certain words are confusing, so I wait to read what has been said on the board.

Marthe: Except the lecturer writes on the board, I feel like a stranger in the class. It has to do with the fact that my English is below standard.

Rachel: I wish all my lecturers could write summaries of what they say in the class. I benefit from power point presentations better than listening to lectures.

Cony: As for me, this does not work. I listen, write and speak English. I don't have to wait for the lecturer to write a summary of what has been said before I understand the lecture. I think it is because I had a bilingual education while in Cameroon.

Violet: Yes as the others have said, I can only understand when the lecturer writes on the board. I do not yet understand many words in English. When the lecturer writes, I write so that on getting home I bring out my dictionary to check unfamiliar words.

A close juxtaposition of the principles of Acharaya (2002) with the narratives of the FSS reveals that personality is important when an attempt is made to comprehend the dynamics involved in processing academic information. Consequently Acharaya's (2002) principle that social and circumstantial interaction among students could be used to explore and consolidate how learning takes place seems valid. Another principle that is validated revolves around what Acharaya (2002) refers to as the method of instruction. A number of the FSS interviewed in the second FGI mentioned the use of power point presentation as a technique that aided how they processed information. I argue that the information processing capacity of FSS could be advanced when facilitators of learning take the effrontery to use technology to enhance learning.

\section{Implications of findings viewed under the theories of action}

First, I use the COP framework by Wenger (1998) to analyse the engagement of FSSwith scholastic activities. As they initially commenced learning, they became novices who needed to interact with lecturers during learning facilitation and peers during group work activities. Since a number of them were shy and outgoing, their levels of engagement with English-speaking students in the COPlikely varied. The variation in personality types likely predisposed them to acquiring the command of English differently. Those who quickly made the transition from French to English did not struggle to process academic information because they were acquainted with the skill of directly processing received information without round trippinginformation. In other words, they were acquainted with the basics of how to engage in cognitive apprenticeship which triggers the capacity to engage in problem-solving initiatives. I use the scholarship of Collins, Brown and Holum (1991, p.3) to elucidate an understanding of how acquired information is processed. Collin et al (1991) note:

In cognitive apprenticeship, one needs to deliberately bring the thinking to the surface, to make it visible, whether it's in reading, writing, problem solving. The teacher's thinking must be made visible to the students and the student's thinking must be made visible to the teacher. .... By bringing these tacit processes into the open, students can observe, enact, and practice them with help from the teacher and from other students. It becomes obvious that the FSS could not calculatingly bring their thinking to the surface in record time, to make it self-perceptible because they had preset ways of processing information via French language. However they were required to transform their preset ways of processing information into a novel one, which entailed the use of English by interacting with stakeholders in the ACOP. Therefore I concur with Mezirow's (1997) suggestion that transformative learning is "the process of effecting changesin a frame of reference" (p.5). English language learning symbolizes a frame of reference which FSS had to transact with French language. The teacher's thinking can only be made visible to the students if adequate transition has been made from one medium of communication to the required one by the FSS. Therefore interaction with MKO likely assisted the FSS who could eloquently communicate in English to acquire the necessary vocabulary to communicate and process information in English instead of utilising French. On the other hand the FSS who did not interact with MKO had arduous trails in processing academic information. Their thinking capacity engaged the use of French 
instead of English because they did not cross the boundary that solicits information processing to English. Consequently they engaged in what I earlier on referred to as information processing by "round tripping." I describe the phenomenon of information processing by "round tripping" as a process of learning "by going round the circle." Learning by going round the circle is challenging because it takes almost twice the effort to translate acquired academic information into a comprehensible format which the cognitive domain can process for meaning making to evolve. The ultimate effect of this learning style culminates in loss of information as learning facilitation commences. This so-called information loss seems to emanate from time lag as the process of round tripping is negotiated. Drawing on Lave's (1988) scholarship, cognitive apprenticeship entails learning by interacting with MKO within a sociocultural milieu. A major departure of cognitive apprenticeship from the tenets of the COP framework involves knowing that cognitive apprenticeship per se, "encourages the student to become the expert" (Collins, Brown \& Holum, 1991, p.16) for meaning making to evolve. In the case of the FSS, their acquisition of English was paramount to becoming an expert because English is the currency of communication in the ACOP.

\section{Conclusion and recommendation}

The refusal of a number of the FSS to adequately interact with more knowledgeable others in the ACOP was tantamount to self-ostracism- a detachment from the "frame of reference", drawing on Mezirow (1997). Self-ostracism likely prevented some of them from engaging with the phenomenon of cognitive apprenticeship, orchestrated by association with students who could communicate with them in English. Drawing on the ideology of Collins et al. (1991), FSS should take the effrontery to learn English in order to function as experts who cognitively engage in processing academic information. Therefore it is suggested that a probable way to avoid processing academic information by "round tripping" is to engage in the process of cognitive apprenticeship with MKO. Cognitive apprenticeship with frames of referenceis envisaged to equip the FSS with the necessary vocabulary that assists in information processing. It occurs to me that there is a point of convergence between COP, frames of reference and cognitive apprenticeship. Furthermore, FSS may only begin to act as experts when they are proficient in English.

I see a correlation between Acharaya's (2002) scholarship and Wenger's (1998) principle of COP because they seem to advocate the same tenets as far as interacting with MKO is concerned. The dissimilarity between them entails knowing that Acharaya (2002) does not amplify the relationship between stakeholders as a community of practice.Lave and Wenger (1991) see the FSS as legitimate peripheral participants as they newly approach EC. Since the involvement of lecturers with FSS, their peers and the interaction between the other stakeholders occurred within the confines of EC, the facilitation of learning by lecturers to FSS and their interaction with peers is regarded as a situated learning experience. These experiences reveal that knowledge and comprehension can be juxtaposed with the experiences of individuals within a sphere of influence. I strongly recommend that emphasis should be made to strengthen the transition of FSS from French to English in order to lessen the effect of round tripping information.

\section{References}

[1]. Acharya, C. (2002). Students' Learning Styles and Their Implications for Teachers, CDTL Brief,5(6). Available from http://www.cdtl.nus.edu. sg/brief/v5n6/.

[2]. Andrade, M. S. (2006). International students in English-speaking universities: Adjustment factors. Journal of Research in International Education, 5(2), 131-154.

[3]. Angelo, T. A. (1993). A Teacher's Dozen: Fourteen General Research-Based Principles for Improving Higher Learning in Our Classrooms. AAHE Bulletin, 45(8), 3-7.

[4]. Bogdan, R.C. \& Taylor, S.J. (1975).Introduction to qualitative research methods: A phenomenological approach to the social sciences. New York: John Wiley.

[5]. Boyle, E., Duffy, T., \& Dunleavy, K. (2003). Learning styles and academic outcome: the validity and utility of Vermunt's Inventory of Learning Styles in a British higher education setting. British Journal of Educational Psychology, 73, 276-290.

[6]. Braun, V. \& Clarke, V. (2006).Using thematic analysis in psychology.Qualitative Research in Psychology, 3, 77-101.

[7]. Chai, F.T., Zaidatol, A.L.P., Soaib, A. \& Rosnani, J. (2013). Learning styles among students pursuing entrepreneurship course in higher education. Pertanika Journal of social sciences and humanities, 21(2), 605-620.

[8]. Cranton, P. (1996). Professional Development as Transformative Learning: New Perspectives for Teachers of Adults. San Francisco: Jossey-Bass.

[9]. Creswell, W. (2007). Educational research: planning, conducting, and evaluating quantitative and qualitative research ( $3^{\text {rd }}$ Edition). Pearson, Merrill Prentice Hall.

[10]. Custers, E., \& Boshuizen, H. (1997). The psychology of learning. In G. R. Norman, C. P. M. van der

[11]. Vleuten, \& D. I. Newble (Eds.), International handbook of Research in medical education (Part One) (p. 163). Boston: Kluwer AcademicPublishers.

[12]. Dunn, R., \& Griggs, S. A. (2003). Synthesis of the Dunn and Dunn learning-style model research: Who, what, when, where, and so what? NY: St. John's University's Center for the Study ofLearning and Teaching Styles.

[13]. Durning, S. J., \& Artino, A.R. (2011). Situativity theory: A perspective on how participants and the environment can interact: AMEE Guide, 52(33), 188-199.

[14]. Fleming, N. D. (2001). Teaching and learning styles: VARK strategies. Christchurch, New Zealand: N. D. Fleming.

[15]. Kim, H.Y. (2011). International graduate students' difficulties: graduate classes as a community of practices. Teaching in higher education, 16(3), 281-292. 
The information processing predicament of non-English-speaking students in an academic.....

[16]. Lave, J. \& Wenger, E. (1991). Situated learning: Legitimate peripheral participation.

Cambridge, UK: Cambridge University Press.

[17]. Lloyd, S. H. (2007). An exploratory study of the relationship between in-training examination percentiles of anesthesiology residents and the Vermunt Inventory of Learning Styles.KansasState University. Manhattan, Kansas.

[18]. Otten, M. (2009). Academicus Interculturalis? Negotiating interculturality in academic communities of practice. Intercultural Education, 20(5), 407-417.

[19]. Othman Talib., Wong Su Luan., Shah Christirani Azhar., \& Nabilah Abdullah. (2009). Uncovering Malaysian students' motivation to learning Science. European Journal of Social Sciences,8(2), 266-276.

[20]. Reyes, R. (2007). A collective pursuit of learning the possibility to be: The CAMP experience assisting situationally marginalized Mexican American students to a successful student identity. Journal of Advanced Academics, 18(4), 618-659.

[21]. Sherry, M., Thomas, P. \& Chui. (2010). International students: a vulnerable population. Higher Education, 60, 33-46.

[22]. Slotnick, H. B. (2001). How doctors learn: education and learning across the medical- school-to practice trajectory. Academic Medicine, 76, 1013-1026.

[23]. Stewart, K. L., \& Felicetti, L. A. (1992). Learning styles of marketing majors. EducationalResearch Quaterly, 15(2), 15-23.

[24]. Steyn, J. (2011). An assessment of the process of student evaluation of teaching effectiveness. Mini-dissertation submitted in partial fulfilment for the degree, magister philosophiae in leadership, performance and change in the Faculty of Management at the University of Johannesburg.

[25]. Tinto, V. (1975). Dropout from Higher Education: A Theoretical Synthesis of Recent Research. Review of Educational Research, $45,89-125$.

[26]. Vermunt, J. D. (1996). Metacognitive, cognitive and affective aspects of learning styles and strategies:A phenomenographic analysis. Higher Educ., 31, 25-50.

[27]. Wenger, E. (1998). Communities of practice: learning, meaning and identity (New York, Cambridge University Press).

[28]. Xue, M. (2013). Effects of group work on English communicative competence of Chinese international graduates in the United States institutions of higher education. The qualitative report, 18(14), 1-19.

[29]. Yeh, C. J., \& Inose, M. (2003). International students' reported English fluency, social support satisfaction, and social connectedness as predictors of acculturative stress. Counselling Psychology Quarterly,16(1), 15-28. 